\title{
Characteristics of Palladium Particles on Tin Dioxide Thin Films Studied by Transmission Electron Microscopy
}

\author{
J. E. Dominguez ${ }^{\mathrm{a}}$, G. W. Graham ${ }^{\mathrm{b}}$ and X. Q. Pan $^{\mathrm{a}}$ \\ ${ }^{a}$ Department of Materials Science and Engineering, The University of Michigan, Ann Arbor, MI \\ 48109. \\ ${ }^{\mathrm{b}}$ Ford Research Laboratory, Ford Motor Co., Dearborn, MI 48121.
}

Metal catalyst dispersion on oxide supports has been extensively studied due to its applications in catalysts for car exhausts and industrial processes. Solid state oxide gas sensors also utilize some form of precious metal dispersion in order to enhance chemical reaction between sensed species and the surface.[1] Also, precious metals decrease the barrier for gas adsorption and thus lower the optimal operating temperature of oxide gas sensors. Nanometersized metal clusters on surfaces at high temperatures are not stable and can be the cause of deleterious effects such as gas sensor drift and non-reproducibility.[2] Transmission electron microscopy can be used as a means to study the morphology and behavior of metal clusters on $\mathrm{SnO}_{2}$ surfaces.

Palladium was deposited by evaporation on tin dioxide single crystal ultrathin films on alumina. Equivalents of 1, 2, 5 and 10 monolayers (ML) were deposited, as checked by x-ray photoelectron spectroscopy. Cross section and plane view samples were made by the common method of polishing and ion milling. The samples were studied within a field emission gun analytical electron microscope (JEOL 2010F) operated at $200 \mathrm{kV}$. In-situ heating experiments were carried out up to $400^{\circ} \mathrm{C}$ using a double-tilt heating stage. Ex-situ heat treatments were performed in a closed chamber under the presence of reducing gases and oxygen at $400^{\circ} \mathrm{C}$.

Figure 1(a) shows the plane view distribution of as-deposited $1 \mathrm{ML} \mathrm{Pd}$ on a $\mathrm{SnO}_{2}$ film. The average particle size is $3 \mathrm{~nm}$ with a narrow length distribution. The spacing between particles ranges between 5 to $10 \mathrm{~nm}$. The particle shape is almost round and no obvious orientation relationship with the substrate is visible. Figure 1(b) shows the same sample after an ex-situ heat treatment consisting of heating in an inert atmosphere up to $400^{\circ} \mathrm{C}$, introducing 4000 ppm hydrogen and oxygen for 30 minutes, and cooling to room temperature in an inert gas. The mean particle size after the heat treatment is $6 \mathrm{~nm}$ with a wider size distribution. Some particles are faceted along low energy surfaces. One example of this is shown in Figure 1 (c). An example of particle sintering is shown in Figure 1(d). In-situ heating experiments were performed to observe particle shape change on heating. Figures 2(a) - (d) are examples of particle coalescence upon heating from $310^{\circ} \mathrm{C}$ to $400^{\circ} \mathrm{C}$. The particles can grow to about twice the initial size, although the kinetics of coalescence was slow and most particles remained with their initial sizes. Figure 3 is a cross section TEM micrograph of the single crystal film with 5 ML coverage. The particles seem to be non-wetting although some interaction with the film is observed in the non-homogeneous film surface morphology.

In conclusion, evaporated palladium nanoclusters on tin dioxide surfaces were studied using analytical electron microscopy. It was found that both temperature and atmosphere have a profound effect on the shape and size of particles. 
References:

[1] P.J. Shaver, Appl. Phys. Lett., 11, 255 (1967)

[2] D. Kohl, Sens. Actuators, 18, 71 (1989)
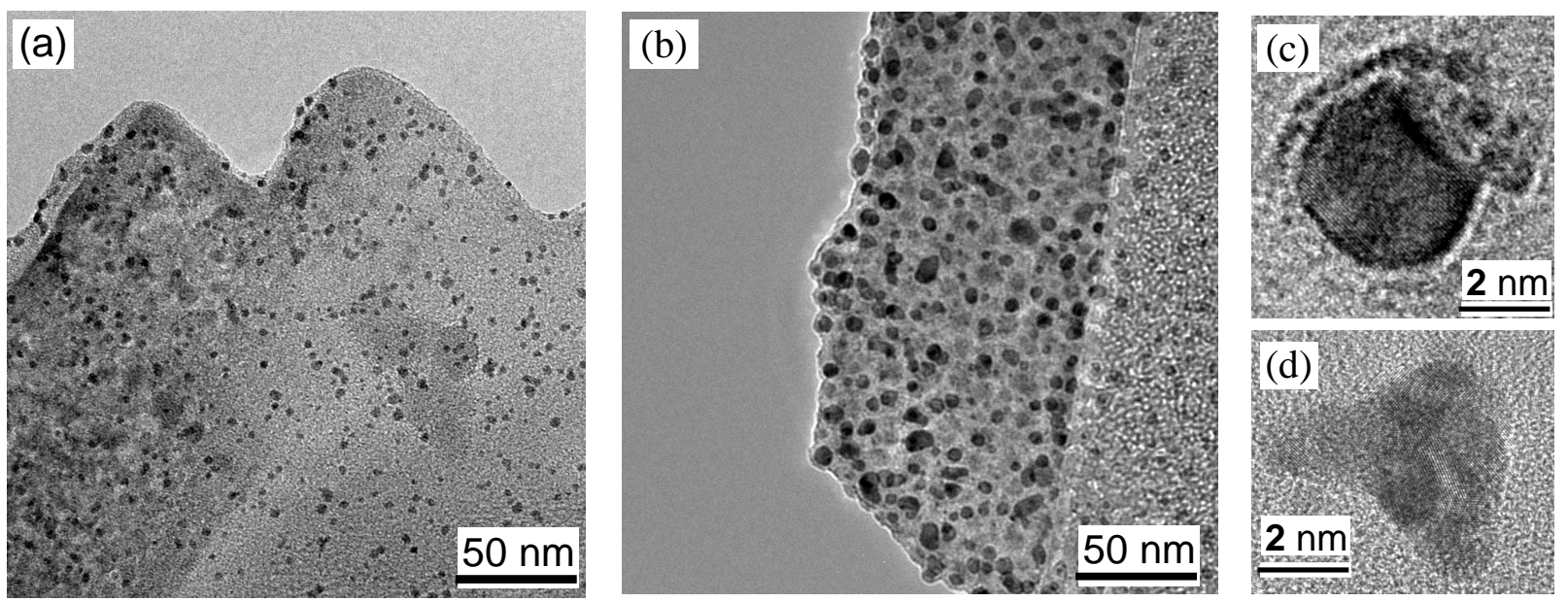

Figure 1: TEM micrographs showing the dispersion of $\mathrm{Pd}$ particles on $\mathrm{SnO}_{2}$ thin film surface (a) before and (b) after heat treatment. (c) A Pd particle shows facets after heating. (d) Clustering of small Pd particles after heating.
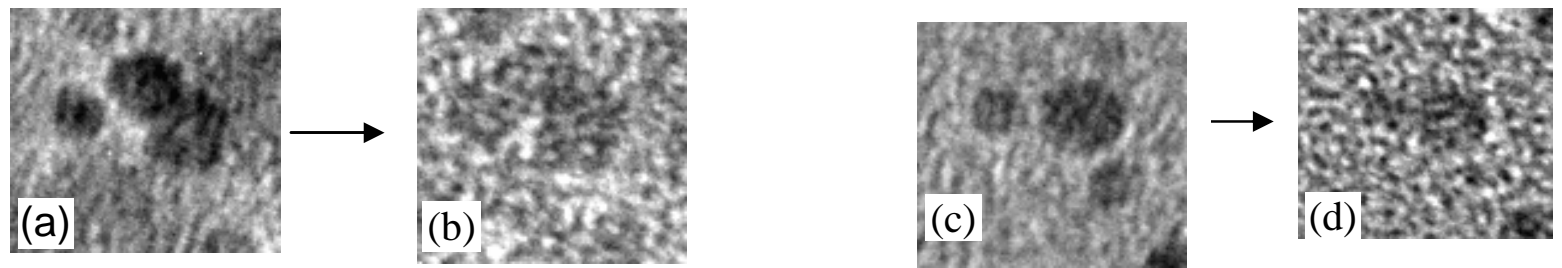

Figure 2: In situ observations of Pd particle sintering during heating treatment at $300^{\circ} \mathrm{C}-420^{\circ} \mathrm{C}$.

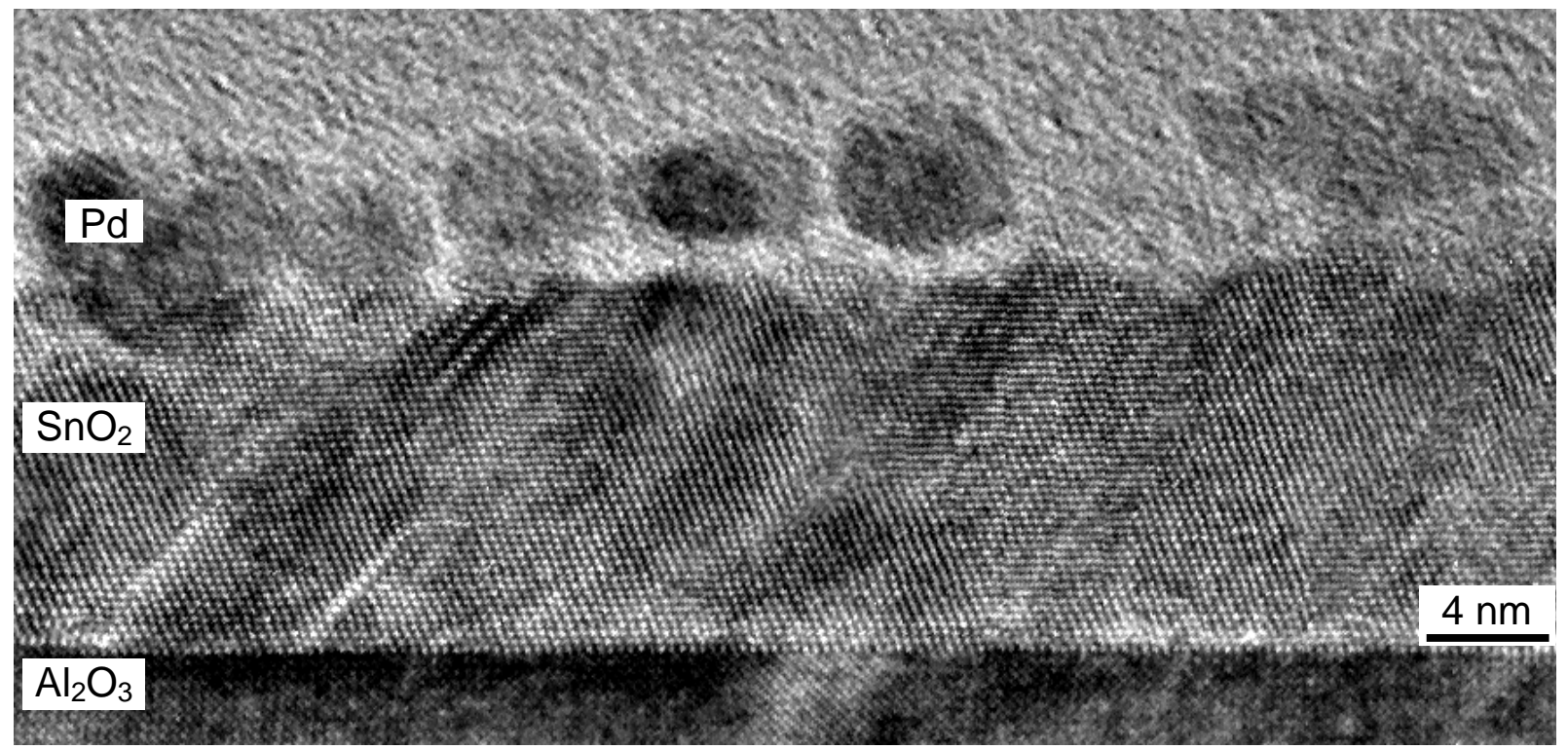

Figure 3: Cross section HRTEM micrograph showing the microstructure of a $\mathrm{SnO}_{2}$ thin film deposited with 5 monolayer of Pd. 